\title{
Altered Representation of Naive and Memory CD8 T Cell Subsets in HIV-infected Children
}

Ronald L. Rabin, Mario Roederer, Yvonne Maldonado, * Ann Petru, ${ }^{\ddagger}$ Leonard A. Herzenberg, and Leonore A. Herzenberg

Department of Genetics and *Division of Pediatric Infectious Diseases, Department of Pediatrics, Stanford University School of

Medicine, Stanford, California 94305; and ${ }^{\ddagger}$ Division of Pediatric Infectious Diseases, Children’s Hospital Oakland,

Oakland, California 94609

\begin{abstract}
CD8 $T$ cells are divided into naive and memory subsets according to both function and phenotype. In HIV-negative children, the naive subset is present at high frequencies, whereas memory cells are virtually absent. Previous studies have shown that the overall number of $\mathrm{CD8} T$ cells does not decrease in HIV-infected children. In studies here, we use multiparameter flow cytometry to distinguish naive from memory CD8 $T$ cells based on expression of CD11a, CD45RA, and CD62L. With this methodology, we show that within the CD8 $\mathrm{T}$ cell population, the naive subset decreases markedly $\left(\mathrm{HIV}^{+}\right.$vs. HIV ${ }^{-}, 190$ vs. 370 cells/ $\left.\boldsymbol{\mu l} ; \boldsymbol{P} \leq \mathbf{0 . 0 0 3}\right)$, and that there is a reciprocal increase in memory cells, such that the total CD8 $T$ cell counts remained unchanged (800 vs. 860 cells $/ \mu \mathrm{l} ; P \leq 0.76)$. In addition, we show that for HIV-infected children, the naive CD8 $T$ cell and total CD4 $T$ cell counts correlate $\left(\chi^{2} P \leq 0.001\right)$. This correlated loss suggests that the loss of naive CD8 $\mathrm{T}$ cells in HIV infection may contribute to the defects in cell-mediated immunity which become progressively worse as the HIV disease progresses and CD4 counts decrease. (J. Clin. Invest. 1995. 95:2054-2060.) Key words: $T$ cell subsets $\bullet$ acquired immunodeficiency syndrome $\bullet T 4$ cells $\bullet T 8$ cells $\cdot$ naive $T$ cells
\end{abstract}

\section{Introduction}

CD8 $\mathrm{T}$ cells, which provide cell-mediated immunity through both cytotoxic and suppresser mechanisms (1), are subdivided by multiparameter flow cytometry $\left(\mathrm{FACS}^{\circledR}\right)$ into subsets according to the differential expression of surface proteins. These subsets are also functionally distinct $(2,3)$. In particular, the subset that expresses the CD45RA surface marker (CD45RA ${ }^{\text {hi }}$ ), which is often referred to as the naive (or virgin) subset, makes a relatively poor cytokine response after $T$ cell receptor stimulation. In contrast, the so-called memory subset, which secretes a wide variety of cytokines in response to $\mathrm{T}$ cell receptor stimulation, expresses CD45RO (another isoform of CD45 [ reference $3]$ ) instead of CD45RA $(3,4)$.

Address correspondence to Leonard A. Herzenberg, Beckman B007, Department of Genetics, Stanford University, Stanford, CA 94305-5125. Phone: 415-723-5054; FAX: 415-725-8564. R. L. Rabin's present address is Laboratory Clinical Investigation, Bldg. 10, Room 11N228, NIAID, NIH, 9000 Rockville Pike, Bethesda, MD 20892.

Received for publication 16 June 1994 and in revised form 12 January 1995.

J. Clin. Invest.

(c) The American Society for Clinical Investigation, Inc.

0021-9738/95/05/2054/07 \$2.00

Volume 95, May 1995, 2054-2060
Several reports have described changes in the CD8 T cell subsets in HIV-infected individuals. The total CD8 $\mathrm{T}$ cell count in blood usually increases initially and only falls late in the disease $(5,6)$. Naive CD8 $T$ cell frequencies, estimated on the basis of CD45RA expression alone, were found to decrease little $(7,8)$ or not at all $(9)$. Memory CD8 T cell frequencies, estimated on the basis of CD45RO expression $(10,11)$, were found to increase in infected children. However, the methodology used in these studies did not definitively resolve the naive and memory subsets, since the shift from CD45RA ${ }^{\text {hi }}$ to CD45RO (CD45RA ${ }^{-}$) is reversible and thus not all CD8 T cells that express the $\mathrm{CD}^{4} \mathrm{RA} \mathrm{A}^{\mathrm{hi}}\left(\mathrm{CD}^{2} 5 \mathrm{RO}^{-}\right)$phenotype are naive $(12,13)$.

Recent studies have identified several other surface markers (14) that provide a better indication of the maturation from naive to memory, e.g., the increase in expression of CD11a $($ LFA-1 $\alpha)(15)$ and the loss of expression of CD62L (L-selectin, LECAM) (16). Therefore, to definitively resolve the memory and naive subsets in studies presented here, we used threecolor multiparameter flow cytometry to simultaneously measure CD8, CD45RA, and either CD11a or CD62L. The results of this study unequivocally demonstrate that HIV-infected children lose a substantial fraction of their naive CD8 $\mathrm{T}$ cells and show a compensatory gain in absolute numbers of memory CD8 T cells.

In an accompanying manuscript (17), we present results from a study of over $250 \mathrm{HIV}$-infected adults showing that, as in studies presented here for HIV-infected children, the naive CD8 subset is lost in parallel with total CD4 T cells. The studies presented here were completed before our adult study was undertaken and provided one impetus for that study. Together, these two studies demonstrate that loss of the functionally important naive T cells from both CD4 and CD8 lineages is characteristic of HIV infection and thus suggest that the loss of these cells may play a major role in the immunopathogenesis of HIV disease.

\section{Methods}

Subjects. 12 HIV-infected children were recruited from the outpatient clinics at Children's Hospital Oakland (CHO $)^{1}$ and seven from Lucille Packard Children's Hospital (LPCH) at the Stanford University Medical Center. All HIV-infected children were receiving antiretroviral therapy (either AZT, DDI, or DDC, or some combination thereof). All children followed at $\mathrm{CHO}$ and two children at $\mathrm{LPCH}$ were receiving monthly intravenous immunoglobulin therapy.

The children who served as HIV-negative controls were recruited from the Pediatric Endocrinology Clinic at LPCH. All children accepted into the study had no risk factors for HIV infection. The HIV-negative

1. Abbreviations used in this paper: $\mathrm{CHO}$, Children's Hospital Oakland; LPCH, Lucille Packard Children's Hospital; PE, phycoerythrin. 
controls either were considered healthy and in no need of therapy or were isolated growth hormone or isolated thyroid hormone deficient and were being treated with replacement therapy. Children were rejected from the study if they were receiving steroid therapy, had a history of cancer, had a CD4/CD8 ratio of $<1$, or were not growing parallel to the normal growth curve.

All participants in this study were recruited for our investigation of glutathione levels in plasma, red blood cells, and peripheral blood mononuclear cell subsets in HIV-infected children. The result of the glutathione analyses will be reported elsewhere. All children were undergoing venipuncture for purposes relevant to their clinic visit. Informed consent was obtained; an additional $3 \mathrm{ml}$ of blood was taken at the time of blood draw and placed in a heparinized tube. All participants had blood taken for a complete blood count, either from the aliquot taken for purposes of this study or because it was clinically indicated. This study was approved by the Institutional Review Boards of Children's Hospital Oakland and Stanford University Medical Center.

Function analysis. Functional analyses for Fig. 2 were performed on PBMC isolated from buffy coats of HIV-negative healthy adults. Cells were stained with fluorescent conjugates of CD8, CD45RA, and CD62L under conditions which do not alter the ability to flux calcium nor to stimulate the cells: briefly, cells were never cooled on ice, but maintained at room temperature; cells were stained for $15 \mathrm{~min}$ with the conjugates in the presence of $0.02 \%$ sodium azide, and washed extensively with azide-free medium.

For the calcium flux experiments, cells were preloaded for $45 \mathrm{~min}$ with $10 \mu \mathrm{g} / \mathrm{ml}$ Indo-1 (Molecular Probes, Inc., Eugene, OR) at $37^{\circ} \mathrm{C}$. Before FACS ${ }^{\oplus}$ analysis, stained cells were warmed for $5 \mathrm{~min}$ to $37^{\circ} \mathrm{C}$. A baseline value for the ratio of Indo-1 fluorescences was collected for $30 \mathrm{~s}$; then $10 \mu \mathrm{g}$ of anti-CD3 (G19-4, kind gift of Dr. J. Ledbetter, Bristol-Meyers Squibb Pharmaceutical Research Institute, Seattle, WA) was added to the cells. FACS ${ }^{\circledR}$ analysis was continued for up to 15 $\mathrm{min}$. The ratio of Indo-1 fluorescences collected in the violet (395-415 $\mathrm{nm}$ ) and in the green (515-560 $\mathrm{nm}$ ) was computed by analogue circuitry (Roederer, M., M. Bigos, T. Nozaki, R. Stovel, D. Parks, and L. A. Herzenberg, manuscript submitted for publication).

For proliferation and cytokine analysis, cells from the CD8 subsets were sorted ( $>99 \%$ purity, as assessed by reanalysis of sorted cells). For proliferation, 5,000 cells were deposited in V-bottom wells containing a total of $100 \mu \mathrm{l}$ of RPMI supplemented with $10 \%$ fetal calf serum, and stimulated with combinations of $20 \mathrm{nM}$ phorbol myristate acetate, $50 \mathrm{ng} / \mathrm{ml}$ anti-CD3 (Leu4), $1 \mu \mathrm{g} / \mathrm{ml}$ Staphylococcus enterotoxin A, and 20,000 irradiated P815/B7 cells (kind gift of Lewis Lanier, DNAX Institute, Palo Alto, CA). Cells were maintained in culture for $3 \mathrm{~d}$; after which $1 \mu \mathrm{Ci}$ of $\left[{ }^{3} \mathrm{H}\right]$ thymidine was added. After an additional $18 \mathrm{~h}$, cells were harvested, and cell-bound radioactivity was quantitated. For cytokine analyses, 50,000 sorted cells were deposited into prewarmed $\left(37^{\circ} \mathrm{C}\right)$ medium containing stimulants. After $6 \mathrm{~h}$, RNA was isolated using RNAzol B (TelTest, Inc., Friendswood, TX). Total cDNA was synthesized using $1 \mu \mathrm{g}$ of random hexamers in a $20-\mu \mathrm{l}$ reaction volume. One-tenth of each cDNA was then amplified by PCR using primers specific for each cytokine; products were separated on a $2 \%$ agarose gel and visualized by ethidium bromide staining. Primers for $\beta$-actin were also used to verify equivalent recovery of mRNA from the cells. The following primer pairs were used: $\beta$-actin, TGACGGGGTCACCCACACTGTGCCCATCTA and CTAGAAGCATTGCGGTGGAC-GATGGAGGG; $\gamma$-IFN, ATGAAATATACAAGTTATATCTTGGCTTT, GATGCTCTTCGACCTCGAAACAGCAT; IL-2, ATGTACAGGATGCAACTCCTGTCT, GTCAGTGTTGAGATGATGCTTTGA; IL-4, ATGGGTCTCACCTCCCAACTGCT, CGAACACTTTGAATATTTCTCTCTCAT; IL-5, GCTAGCTCTTGGAGCTGCCTAC, TCAACTTTCTATTATCCACTCGGTGTTCATTAC; IL-10, ATGCCCCAAGCTGAGAACCAAGACCC, TCTCAAGGGGCTGGGTCAGCTATCCC; GM-CSF, ATGTGGCTGCAGAGCCTGCTGC, CTGGCTCCCAGCAGTCAAAGGG.

Materials. The following conjugated monoclonal antibodies were kind gifts of Becton Dickinson Immunocytometry Systems, (San Jose, CA): phycoerythrin-conjugated Leu-8 (PE-Leu-8, CD62L), PE-LeuM5 (CD11c), fluorescein isothiocyanate (FITC) Leu 18 (CD45RA), and PE-Leu 18. The following conjugated monoclonal antibodies were obtained from PharMingen (San Diego, CA): FITC-HIT3a (CD3), FITC-3G8 (CD16), biotin and PE-RPA-T8 (CD8), Cy5-PE (CyChrome $^{\mathrm{TM}}$ ) conjugated RPA-T4 (CD4), FITC-CI111 (CD11a), and Cy5-PE HI30 (CD45). When biotin-conjugated monoclonal antibodies were used, they were revealed with Cy5-PE conjugated avidin (PharMingen).

For purposes of this report, we stained for the following combinations of immunophenotype surface markers (FITC, PE, Cy5-PE): CD16, CD11c, and CD45; CD3, CD4, and CD8; CD11a, CD45RA, and CD8; CD45RA, CD62L, and CD8. The glutathione stain does not affect the intensity nor the ability to detect any of the immunofluorescence reagents (data not shown; see reference 18).

Multiparameter flow cytometry. Peripheral blood mononuclear cells (PBMC) were isolated from whole blood by Ficoll-Hypaque density centrifugation (Ficoll-Paque was obtained from Pharmacia AB, Uppsala, Sweden). The PBMC were washed and suspended in RPMI media deficient in biotin, phenol red, and riboflavin and stained for intracellular glutathione concentrations as described previously (18). The PBMC were then washed, and, at $4^{\circ} \mathrm{C}$, stained with the combinations of fluorochrome-conjugated monoclonal antibodies listed above. The stained PBMC were then resuspended in $0.8 \%$ paraformaldehyde to inactivate HIV and analyzed on a dual laser (argon $360 \mathrm{~nm}$, argon $488 \mathrm{~nm}$ ) flow cytometer (FACStar Plus ${ }^{\circledR}$; Becton Dickinson Immunocytometry Systems) interfaced to a VAX 6300 computer (Digital Computer, Maynard, MA) and FACS/DESK ${ }^{\oplus}$ software (19). Independent analyses have shown that staining for intracellular glutathione does not affect subsequent staining for surface marker proteins and fixing with paraformaldehyde alters neither the representation of subsets nor surface antigen quantitation.

Total counts of all subsets of $T$ cells were calculated as follows: (percentage of subset/percentage of lymphocytes) $\times$ absolute lymphocyte count. The percentage of CD4 and CD8 T cells was calculated from the percentage of $\mathrm{CD}^{+} \mathrm{CD}^{+}$or $\mathrm{CD}^{+} \mathrm{CD}^{+} \mathrm{T}$ cells (Table I). The percentage of lymphocytes was calculated as the percentage of cells expressing the common leukocyte antigen (all isoforms of CD45), which are not monocytes $\left(\mathrm{CD} 11 \mathrm{c}^{\mathrm{hi}}\right)$ or contaminating granulocytes $\left(\mathrm{CD} 11 \mathrm{c}^{\text {lo }}, \mathrm{CD} 16^{\mathrm{hi}}\right)$. The absolute lymphocyte count was taken from the complete blood count.

To define subsets, we used only CD8 ${ }^{\text {hi }}$ expression to identify CD8 $\mathrm{T}$ cells. To exclude natural killer cells (which are CD8 ${ }^{\text {lo }}$ ) we used a very bright reagent which segregates them from CD8 $\mathrm{T}$ cells.

Statistical analysis. Differences between HIV-negative control and HIV-infected children were evaluated by Mann-Whitney U nonparametric testing. Linear correlations between absolute counts (cells/microliter) of lymphocyte subsets with each other were evaluated by least squares regression analysis. Frequency testing of groups of study subjects was done by $\chi^{2}$ analysis. All statistical evaluations were performed with StatView 4.0 software (Abacus Concepts, Berkeley, CA) and an Apple Macintosh microcomputer (Apple Computer, Cupertino, CA). All $P$ values are two tailed.

\section{Results}

Study subjects. The study groups consisted of 19 HIV-infected and 17 HIV-negative control children (Table I). Of the HIVnegative control children, five (29\%) children with congenital hypothyroidism were being treated appropriately with L-thyroxine (Synthroid; Boots Pharmaceuticals, Lincolnshire, IL), and the five $(29 \%)$ who are growth hormone deficient were receiving recombinant human growth hormone (Protropin; Genentech, South San Francisco, CA). Those diagnosed as normal variant short stature (29\%) and "other" (12\%) were not receiving therapy of any kind.

Of the 19 HIV-infected children, 5 (26\%) acquired the virus through contaminated blood products; 3 of these children have AIDS. The remaining 14 (74\%) HIV-infected children acquired the virus vertically; 5 of them have AIDS. 
Table I. Study Subjects

\begin{tabular}{lcc}
\hline & HIV negative control & HIV-infected \\
\hline Age & 1 & \\
$10-24$ mo & 4 & 1 \\
$2-4$ yr & 3 & 7 \\
$5-8$ yr & 6 & 4 \\
$9-13$ yr & 3 & 7 \\
$14-16$ yr & 9.8 & 0 \\
Median yr & & 5.7 \\
Sex & 12 & 8 \\
Male & 5 & 11 \\
Female & & \\
Mode of transmission & & $14(4)^{*}$ \\
Vertical & & \\
Horizontal & & \\
Diagnosis & 5 & \\
CHT & 5 & \\
GHD & 526 \\
NVSS & 5754 \\
Other & 2 & \\
T cell counts (median) & & \\
CD4 & & \\
CD8 & 1320 & \\
& &
\end{tabular}

* In parentheses, number of children with AIDS. ${ }^{\ddagger} C H T$, congenital hypothyroidism; $G H D$, growth hormone deficiency; NVSS, normal variant short stature; Other are healthy children in whom disease has been ruled out. ${ }^{\circledR} P<0.0005$ by Mann-Whitney $\mathrm{U}$ nonparametric testing.

Multiparameter FACS ${ }^{\circledR}$ analysis of CD8 T cells. Representative CD8 T cell subsets are shown in Fig. 1. Flow cytometric analysis for three surface markers identifies a subset of cells which expresses low levels of CD11a $\left(\mathrm{CD} 11 \mathrm{a}^{\text {lo }}\right)$ and high levels of CD45RA (CD45RA ${ }^{\text {hi }}$, Fig. 1, top row, solid arrows). A similar analysis identifies a subset which is CD45RA ${ }^{\text {hi }}$ and $\mathrm{CD}^{2} \mathrm{~L}^{\text {hi }}$ (Fig. 1, bottom row, solid arrows). This subset fits previous definitions of the naive subset of CD8 T cells (16, 20 ). We have recently shown by four-color immunofluorescence analysis that all cells that fit the naive phenotype $\left(\right.$ CD11a $^{\text {lo }}$, CD $45 R A^{\text {hi }}$ ) are also CD62L ${ }^{\text {hi }}$ (data not shown); however, not all CD1 $1 \mathrm{a}^{\text {lo }}$ cells are CD45RA ${ }^{\text {hi }}$. Thus, it is necessary to simultaneously measure three antigens (CD8, CD45RA, and CD11a or CD62L) to uniquely identify the naive cells.

In addition to the naive subset, Fig. 1 (left) shows three other subsets of CD8 T cells. For the purposes of this report, we refer to all of these subsets as memory cells because they are all $\mathrm{CD}_{11 \mathrm{a}^{\mathrm{hi}}}(15)$. These subsets of memory or effector cells further segregate on the basis of CD45RA and CD62L expression (Fig. 1, bottom row). In general, the most frequent of these is the $\mathrm{CD}^{2} 5 \mathrm{RA}^{-}, \mathrm{CD}^{-} \mathrm{L}^{-}$subset (Fig. 1, bottom row, hollow arrows); additional memory subsets express only CD62L or only CD45RA.

Functional analysis of CD8 subsets. To confirm the previously identified functional differences between naive and memory CD8 subsets, we did three kinds of analyses on the naive and memory subsets: cytoplasmic calcium flux (a prerequisite event for proliferation, and the extent of the flux is related to proliferative capacity ); proliferative response to several mitogenic stimuli, measured by DNA synthesis; and cytokine mRNA profiles in response to several stimuli, determined by reverse
PCR. Fig. $2 A$ shows that the different subsets have substantially different capacities to transport calcium in response to the CD3 triggering. The naive cells respond very well, with a vigorous and sustained increase in cytoplasmic calcium. In contrast, the memory subsets show a much weaker flux. As expected, the ability to flux calcium is correlated with the subsequent mitogenic capacity of these cells (Table II), i.e., the naive cells proliferated to a greater extent than the memory subsets. Finally, data from a limited survey of the cytokine profiles of the subsets (Fig. $2 B$ ) are also consistent with the known phenotype of naive and memory cells. That is, the naive cells have a much more restricted cytokine profile, while only the memory subsets made the typical memory/effector cytokines IL-4, IL-5, or $\gamma$-IFN.

Loss of naive CD8 and increase in memory CD8 T cells. Fig. 1 demonstrates that the majority of the CD8 T cells in HIV-negative control children are naive (middle, solid arrows). In contrast, the representative plots of HIV-infected children (Fig. 1, right) demonstrate a decrease of the naive subset and a commensurate increase of the memory subsets of CD8 T cells.

Summary data for all the children in the study are shown in Fig. 3. In agreement with previous reports, the total CD8 $\mathrm{T}$ cell count $(5,6)$ and the frequency of the CD45RA ${ }^{\text {hi }}, C D 8$ $T$ cells (previously taken as the naive subset) do not differ significantly (7-9) between the HIV-infected and control children. In contrast, the naive subset as we define it (CD45RA $^{\text {hi }}$, CD11 $a^{\text {lo }}$, CD62 $\left.\mathrm{L}^{\text {hi }}\right)$ is clearly decreased in HIV-infected children in absolute number $(P \leq 0.003)$, as well as percentage of total CD8 $\mathrm{T}$ cells. While all memory subsets increased, the most significant increase was found for the CD45RA ${ }^{-} \mathrm{CD} 62 \mathrm{~L}^{-}$ subset $(P \leq 0.0004)$. The other memory subsets are also increased, although not to the same extent (HIV-infected versus HIV-negative controls, $P \leq 0.05$ for both subsets). Therefore, the increase in the total CD8 counts in HIV-infected children is due exclusively to an expansion of the memory subsets of CD8 $\mathrm{T}$ cells.

No differences were found for a variety of other variables. Within the group of HIV-infected children, we found no differences between those who acquired HIV horizontally or vertically or between those with or without AIDS (not shown). Similarly, among the HIV-negative controls, there were no differences between those who were or were not receiving growth hormone or L-thyroxine (not shown). In addition, we found no correlation between age and the number or percentage of naive CD8 $\mathrm{T}$ cells in either the HIV-negative or the HIV-infected children (not shown). Furthermore, we found no correlation between disease severity and either CD4 or CD8 counts.

The naive CD8 $T$ cell count correlates with the total CD4 count in HIV-infected children. Fig. 4 shows that the HIVinfected children whose naive CD8 $\mathrm{T}$ cell counts are low also have low total CD4 counts. In essence, all but one of the HIVinfected children whose naive CD8 $\mathrm{T}$ cell counts fell below their median ( 186 cells $/ \mu \mathrm{l}$ ) have CD4 T cell counts that also fall below their median ( 526 cells $/ \mu \mathrm{l}$ ). Similarly, all but one of the HIV-infected children with high CD4 counts had high naive CD8 T cell counts. This correlation is significant by $\chi^{2}$ analysis and Fisher's exact test $(P \leq 0.001)$.

The specific clustering of CD4 counts and naive T cell counts in the HIV-infected children is also visible in a regression analysis of the data discussed above (see Fig. 4). For simplicity, regression lines are not shown in the figure. However, least squares linear analysis computed for the data demonstrates that CD4 $\mathrm{T}$ cell counts correlate better with naive CD8 $\mathrm{T}$ cell counts 


\section{Healthy Adult}

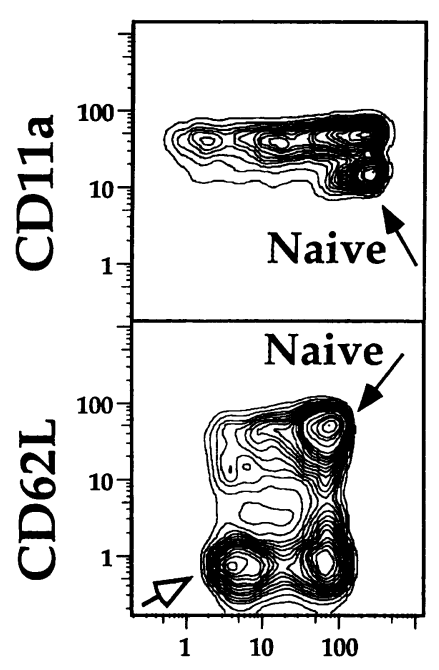

HIV-negative Control Children

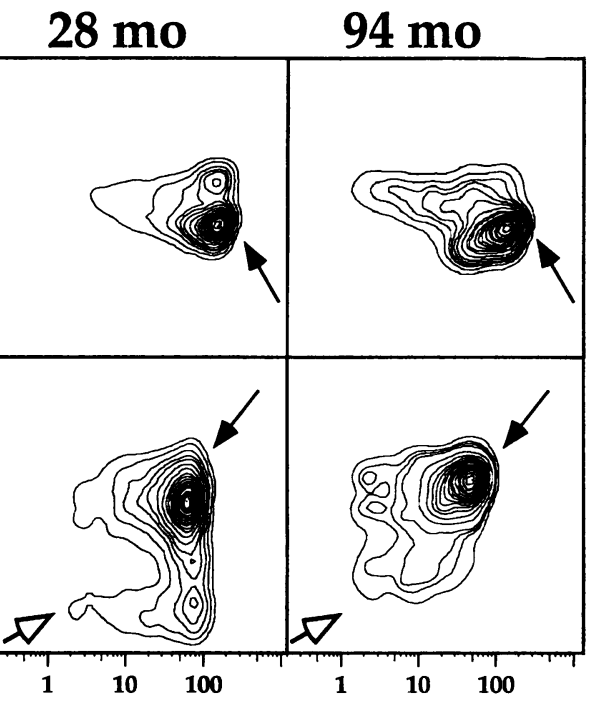

HIV-Infected

Children

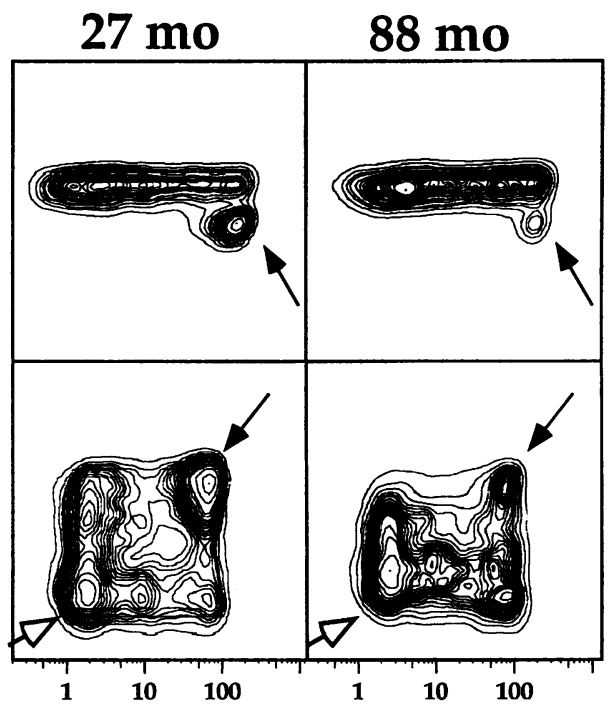

\section{CD45RA}

Figure 1. Representative 5\% probability contour plots of CD8 T cells from a healthy adult, two HIV-negative control children, and two HIV-

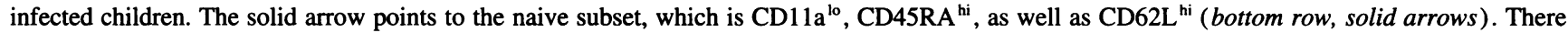
are three subsets of memory CD8 $\mathrm{T}$ cells, all of which are CD11 $\mathrm{a}^{\mathrm{hi}}$ (top row). These memory subsets can be distinguished from each other according to CD45RA and CD62L expression (bottom row). The memory subset with the highest frequency is CD45RA ${ }^{-}, \mathrm{CD}^{-} \mathrm{L}^{-}$. The CD8 $\mathrm{T}$ cells of HIV-negative children (middle) are virtually all naive. The frequency of the naive subset is substantially decreased in HIV-infected children (right), and, conversely, the frequency of all memory subsets is increased. Although the percentage of naive CD8 T cells is decreased, the phenotype of the remaining cells is unchanged. Note that for the upper panels we used PE-conjugated CD45RA, while for the lower panels we used FITCconjugated CD45RA; hence the apparent difference in staining intensity.

A

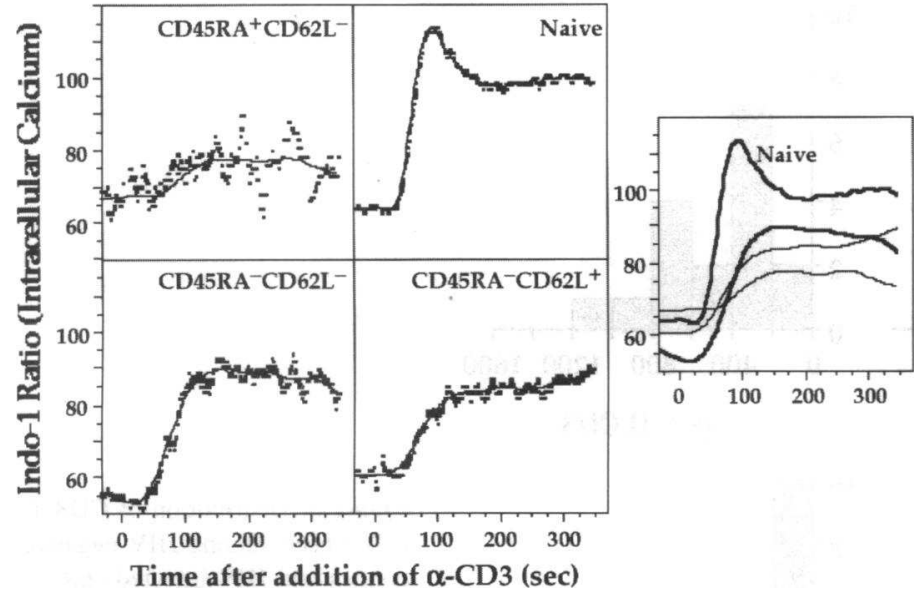

B

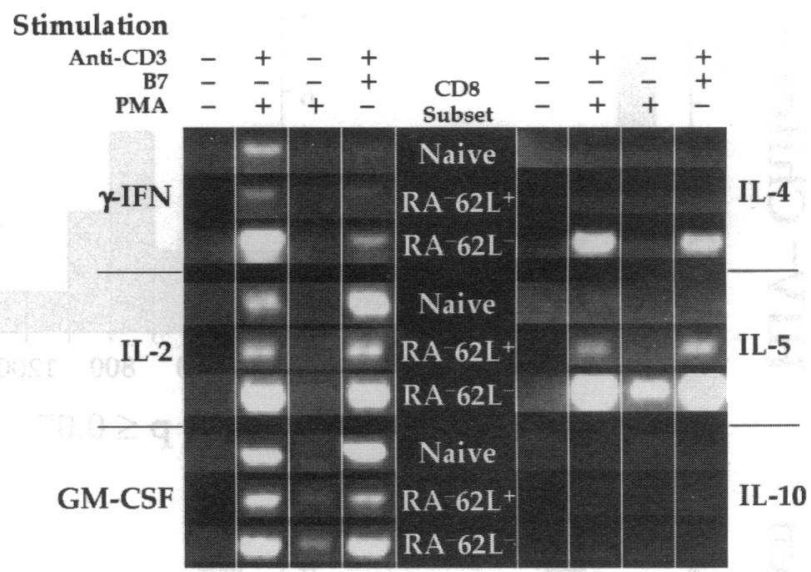

Figure 2. Functional analysis of CD8 T cell subsets as defined in Fig. 1. (A) The ability of the different subsets to flux calcium after CD3 stimulation is markedly different. While the kinetics is roughly equivalent (influx begins $\sim 45 \mathrm{~s}$ after stimulation), the extent of the flux and the resulting quasi-equilibrium concentration of calcium are markedly higher in the naive cells. The CD45RA ${ }^{+} \mathrm{CD}_{2} \mathrm{~L}^{-}$memory subset has at best a nominal calcium flux. Each point represents the average value for $10 \mathrm{~s}$ of data $(\sim 200 \mathrm{cells} / \mathrm{s}$ for the naive subset; as low as 30 cells/s for the rarest memory population). The data points for the naive are mostly hidden under the curve. The four curves are reproduced in the right panel for comparison. (B) A survey of cytokine messages made by three of the subsets in response to stimulation. Cells from the CD8 subsets were sorted to purity and cultured for $6 \mathrm{~h}$ with various stimulants; cytokine expression was assessed by reverse PCR. The naive cells do not express message for IL-4 or IL5 , and extremely low levels of $\gamma$-IFN. None of the CD8 subsets made detectable IL- 10 . 
Table II. Proliferative Capacity of CD8 Naive and Memory Subsets

\begin{tabular}{|c|c|c|c|c|c|}
\hline \multirow[b]{2}{*}{ Stimulus } & \multirow{2}{*}{$\begin{array}{l}\text { Naive } \\
\text { (cpm)* }\end{array}$} & \multicolumn{2}{|c|}{$\mathrm{CD} 45 \mathrm{RA}^{-} \mathrm{CD}^{2} \mathrm{~L}^{-}$} & \multicolumn{2}{|c|}{$\mathrm{CD} 45 \mathrm{RA}^{-} \mathrm{CD}^{2} \mathrm{LL}^{+}$} \\
\hline & & $(\mathrm{cpm})^{*}$ & $(\text { fold })^{\ddagger}$ & $(\mathrm{cpm})^{*}$ & (fold) \\
\hline Unstimulated & 17 & nd & & 10 & \\
\hline Leu4 + PMA & 1600 & 640 & 2.4 & 650 & 2.5 \\
\hline Leu4 + B7 & 5050 & 2010 & 0.8 & 6500 & 2.5 \\
\hline SEA & 140 & 39 & 8.7 & 24 & 4.9 \\
\hline SEA + PMA & 690 & 300 & 1.8 & 390 & 2.4 \\
\hline
\end{tabular}

* Mean counts per minute for triplicate wells $(5,000$ cells per V-bottom well; 4-d stimulation). Standard deviations were all $<15 \%$ of the mean. ₹ The ratio of the proliferation signal for the naive cells to the proliferation signal for the memory population (background was subtracted from each value before division).

in HIV-infected children than in HIV-negative children ( $r^{2}$ for HIV-negative control, 0.38; for HIV-infected, 0.54).

Total CD8 T cell counts, in contrast, show essentially no correlation with CD4 counts either in HIV-negative or in HIVinfected children. That is, there is no significant correlation of total CD4 and CD8 counts as measured by $\chi^{2}$ analysis of HIVinfected children above and below the medians for CD4 and CD8 T cells $(P \leq 0.07)$; and there was less correlation by linear regression analysis ( $r^{2}$ for HIV-negative control, 0.42 ; for HIV-infected, 0.29).

\section{Discussion}

In studies presented here, we demonstrate the selective loss of a functional subset of CD8 T cells in HIV-infected children, i.e., naive $\mathrm{CD} 8 \mathrm{~T}$ cells $\left(\mathrm{CD} 8{ }^{+} \mathrm{CD} 2 \mathrm{~L}^{+} \mathrm{CD}^{+}\right.$45A $\left.{ }^{+}\right)$. In addition, we present novel data which demonstrate that the number of naive CD8 $\mathrm{T}$ cells correlates with the number of total CD4 $\mathrm{T}$ cells in all children, particularly those who are HIV-infected.

Functionally, naive $\mathrm{T}$ cells are defined as cells which have recently emigrated from the thymus and have a predominantly proliferative response when exposed to cognate antigens for the first time $(3,21)$. This encounter with antigen also triggers the naive $\mathrm{T}$ cell to differentiate and express the surface phenotype of memory cells (16). Thereafter, when a memory $T$ cell encounters its cognate antigen, the response is predominantly one of cytokine secretion rather than proliferation (3). The definitions of naive and memory are based on studies published by others $(15,16)$; we confirmed these functional differences in the subsets defined here: the naive cells show a greater capacity to flux calcium and to proliferate in response to mitogenic stimuli, but have a more limited cytokine response than memory/ effector cells.

Our studies, which demonstrate that naive CD8 T cells decrease substantially in HIV-infected individuals, conflict with earlier observations indicating that naive CD8 $\mathrm{T}$ cell counts either decrease slightly or remain unchanged $(8,9,11,22-24)$. These differences are explained by the difference in methodology used to identify the naive cells: only the use of the threecolor immunofluorescence profile that we use here resolves these cells completely from the memory subsets (for further

\section{Total}

\section{CD8+}
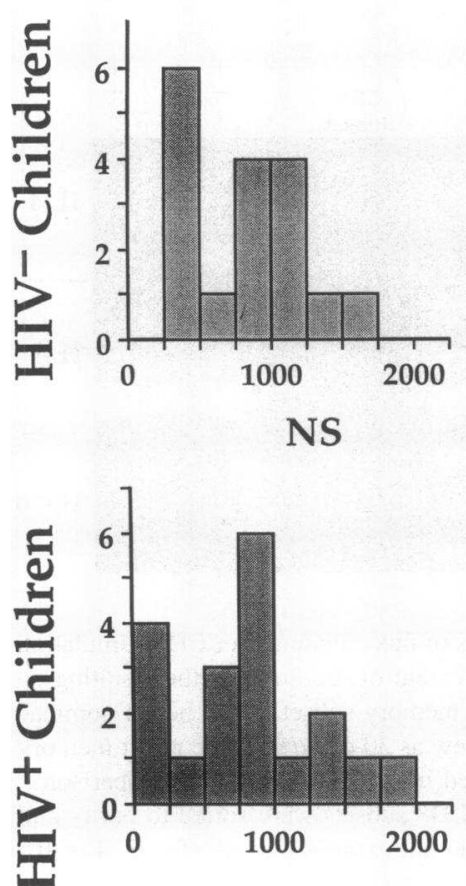
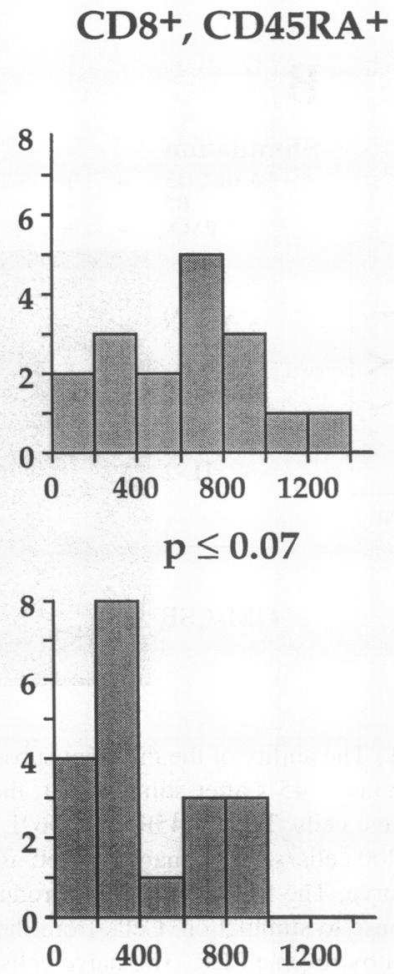

cells / $\mu$ l of blood
Naive CD8+, CD45RA+, CD11a lo
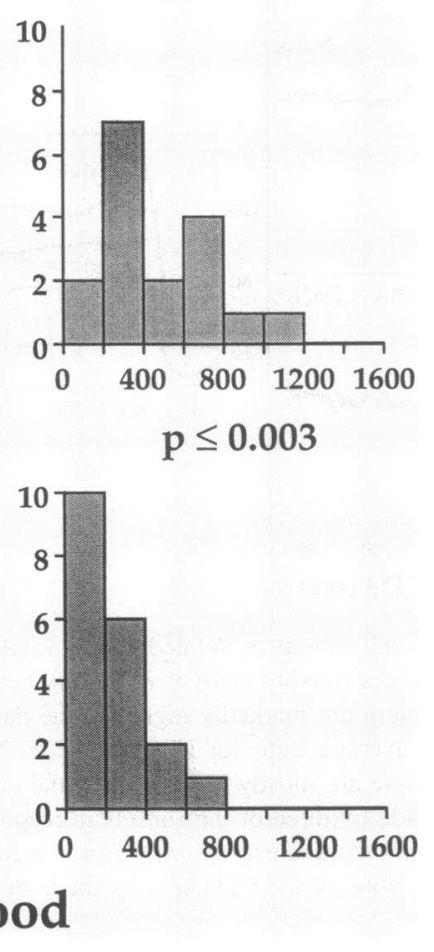

Figure 3. Distribution of CD8 T cell subsets among HIV-negative control and HIV-infected children. Since CD45RA alone is insufficient to distinguish naive from memory cells, there was no statistically significant difference in the numbers of cells defined only on the basis of this marker (center). However, there is a very large difference when the naive cells are uniquely identified on the basis of three markers (right). 


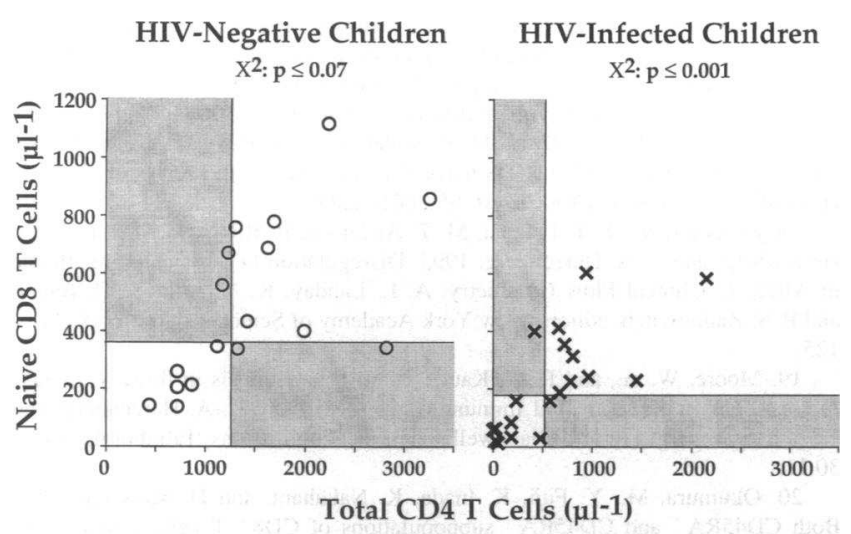

Figure 4. Total CD4 $\mathrm{T}$ cell count and naive CD8 $\mathrm{T}$ cell count correlate in HIV-negative control children (left) and HIV-infected children (right). The lines segregate the groups of children into quadrants according to median total CD4 $\mathrm{T}$ cell counts and naive CD8 $\mathrm{T}$ cell counts within each group. Of the $19 \mathrm{HIV}$-infected children, 9 are above the medians for both CD4 and naive CD8 T cell counts, and 8 are below both medians. Of the 17 control children, 7 are above, and 6 are below both of their respective medians. The correlation of CD4 and naive CD8 $\mathrm{T}$ cell counts among HIV-negative children bordered on significance $\left(\chi^{2}, P \leq 0.06\right)$; for HIV-infected children, it was highly significant ( $P$ $<0.001)$.

discussion, please see Results and our accompanying manuscript [17]). Our data on memory subset counts are consistent with previous observations that memory CD8 T cells increase $(11,25)$. However, we extend these earlier findings by demonstrating here that this increase is most marked in a specific subset $\left(\mathrm{CD}^{+} \mathrm{CD}^{+}\right.$5RA- $\left.\mathrm{CD}^{-} 2 \mathrm{~L}^{-}\right)$.

Studies here compare HIV-infected children with control patients who were seen in a large pediatric endocrinology clinic. All of the control children were growing parallel to the normal growth curve and none was receiving steroid therapy; most were being followed for isolated problems such as congenital hypothyroidism or possible or actual growth hormone deficiency. Children with multiple endocrinopathies, such as hypopituitarism, were rejected from this study because growth hormone affects CD4 T cell counts in these children (25). Since findings with control children receiving therapy did not differ from findings with controls who were in no need of therapy (e.g., normal variant short stature), it is unlikely that the corrected hormonal deficiencies of some of the children confound their immunologic status.

The observations we describe are also not confounded by possible differences between chronological and physiologic ages in our control and HIV-infected groups of children, nor the broad age range of the children we studied. Okumura and colleagues (26), using CD8 $\mathrm{T}$ cell subset definition criteria similar to those we used (CD11a, CD45RA), demonstrated changes in the frequencies of CD8 $\mathrm{T}$ cell subsets that begin to occur during adolescence in healthy individuals. The children we studied in the HIV-negative control and HIV-infected groups were all under $13 \mathrm{yr}$ of age. In these preadolescent children, we found no evidence that frequency of subsets correlates with age. Thus, we agree with Okumura that preadolescent children have not yet begun to show age-related changes in CD8 $\mathrm{T}$ cell naive and memory subset patterns, and conclude that age is not a factor in our study.

There are several possible mechanisms for the loss of circu- lating naive CD8 T cells in HIV-infected children. For example, it could be due to HIV infection of early double-positive progenitors in the thymus. Bonyhadi and colleagues (27) have shown that $\mathrm{CD}^{+}{ }^{+} \mathrm{CD} 8{ }^{+} \mathrm{T}$ cell progenitors can be infected and thereby die before emigrating from the thymus and entering the peripheral circulation as naive $T$ cells. This mechanism could be quite important in children because the thymopoiesis is extremely active before adolescence.

Alternatively, the decrease in naive CD8 $\mathrm{T}$ cells in children may not be primarily due to HIV infection, but may be secondary to complications of HIV which are perhaps common to all chronic infections or inflammatory states. In fact, CD8, CD45RA $^{\text {hi }} \mathrm{T}$ cells are decreased in adults with long-standing insulin-dependent diabetes (28) and vitamin A-deficient children have increased CD45RO ${ }^{\text {hi }}$, CD8 T cells (29). Similarly, chronic alcohol consumption by adults frequently results in a loss of $\mathrm{T}$ cell function and a concomitant decrease in the representation of naive $\mathrm{T}$ cell subsets (30). But whether the decline in naive CD8 T cells is unique to HIV or occurs more generally in severe disease is irrelevant to the immunopathogenic consequences of the loss of these cells. Since naive T cells are crucial to immune responsiveness, their loss may have as severe an impact in HIV disease as the overall loss of CD4 T cells.

In particular, HIV-infected children (and adults) with low CD4 T cell counts are more susceptible to infection with opportunistic organisms such as Pneumocystis carinii and Mycobacterium avium intracellulare. This immune deficiency has been ascribed to the decrease of CD4 T cells. However, our data show that the naive CD8 $\mathrm{T}$ cell count correlates with the total CD4 count. Thus, the immunodeficiency in HIV disease could be mediated either by low CD4 counts, low naive $\mathrm{CD} 8 \mathrm{~T}$ cell counts, or, most likely, a combination of both in conjunction with other factors.

In conclusion, we have demonstrated a clear loss of the naive subset of CD8 $\mathrm{T}$ cells and an increase in CD8 memory $\mathrm{T}$ cells in HIV-infected children. In an accompanying manuscript, we show that this loss also occurs in adults (17) and that it is similarly correlated with the loss of total CD4 cells. We suggest that these changes may contribute to the increased susceptibility to infection and the loss of cell-mediated immunity that is observed in HIV-infected individuals. In addition, because naive $\mathrm{T}$ cells are so important for the generation of new immune responses, we suggest that the naive counts be used to stratify clinical trials of therapeutic vaccinations and immunomodulatory therapies in HIV disease.

\section{Acknowledgments}

We are grateful to the following people for their assistance in conducting this study: Dr. Darrell M. Wilson and Dr. Raymond L. Hintz of the Division of Pediatric Endocrinology, Stanford University, for allowing us to recruit their patients for participation in this study as control subjects; Jim Riddell, R.N., Deborah Jett, R.N., Marjorie Hammer, R.N., and Peggy Macy, M.S.W., of CHO, and Barbara Sullivan, R.N., of the Division of Pediatric Infectious Diseases, Stanford University, for assistance in recruiting children and obtaining informed consent; and Eric Wunderlich for his expert technical assistance. We especially thank Dr. Thomas Merigan for making the Stanford Center for AIDS Research available for these studies, and Dr. David Parks and the other members of the Stanford Shared FACS ${ }^{\circledR}$ facility staff for flow cytometry support.

Mario Roederer is a Senior Fellow of the Leukemia Society of America. This work was supported in part by National Institutes of Health grants AI-31770, LM-04836, and CA-42509. 


\section{References}

1. Mackewicz, C., and J. A. Levy. 1992. CD8 ${ }^{+}$cell anti-HIV activity: nonlytic suppression of virus replication. AIDS Res. Hum. Retroviruses. 8:1039-1050.

2. Sohen, S., D. Rothstein, T. Tallman, D. Gaudette, S. Schlossman, and C. Morimoto. 1990. The functional heterogeneity of $\mathrm{CD8}^{+}$cells defined by antiCD45RA (2H4) and anti-CD29 (4B4) antibodies. Cell. Immunol. 128:314-328.

3. De Jong, R., M. Brouwer, F. Miedema, and R. A. van Lier. 1991. Human $\mathrm{CD8}^{+} \mathrm{T}$ lymphocytes can be divided into $\mathrm{CD}^{+} 5 \mathrm{RA}^{+}$and $\mathrm{CD}^{-} 5 \mathrm{RO}^{+}$cells with different requirements for activation and differentiation. J. Immunol. 146:20882094.

4. Clement, L. T. 1992. Isoforms of the CD45 common leukocyte antigen family: markers for human T-cell differentiation. J. Clin. Immunol. 12:1-10.

5. McGrath, M. S. 1990. T cell abnormalities. In AIDS Knowledge Base. Textbook on HIV from the University of California, San Francisco and San Francisco General Hospital. P. T. Cohen, M. A. Sande, and P. A. Volberding, editors. Medical Publishing Group, Waltham. 3.2.2-1-3.

6. Steihm, E. R., and D. W. Wara. 1991. Immunology of HIV. In Pediatric AIDS: The challenge of HIV infection in infants, children, and adolescents. P. A. Pizzo and C. M. Wilfert, editors. Williams and Wilkins, Baltimore. 95 112.

7. Prince, H. E., S. Kleinman, C. Czaplicki, J. John, and A. E. Williams 1990. Interrelationships between serologic markers of immune activation and $T$ lymphocyte subsets in HIV infection. J. Acquired Immune Defic. Syndr. 3:525530.

8. Giorgi, J. V., and R. Detels. 1989. T-cell subset alterations in HIV-infected homosexual men: NIAID multicenter AIDS cohort study. Clin. Immunol. Immunopathol. 52:10-18.

9. Teitel, J. M., J. J. Freedman, M. B. Garvey, and M. Kardish. 1989. Twoyear evaluation of clinical and laboratory variables of immune function in 117 hemophiliacs seropositive or seronegative for HIV-1. Am. J. Hematol. 32:262272 .

10. Froebel, K. S., K. V. Doherty, J. A. Whitelaw, R. A. Hague, J. Y. Mok, and A. G. Bird. 1991. Increased expression of the CD45RO (memory) antigen on T cells in HIV-infected children. AIDS (Phila.). 5:97-99.

11. Borkowsky, W., T. Moore, K. Krasinski, K. O. Ajuang-Simbiri, and R. Holzman. 1992. Evolution of phenotypic memory T cells in HIV-1 infected infants and children. Clin. Immunol. Immunopathol. 63:280-284.

12. Bell, E. B., and S. M. Sparshott. 1990. Interconversion of CD45R subsets of CD4 T cells in vivo. Nature (Lond.). 348:163-166.

13. Rothstein, D. M., A. Yamada, S. F. Schlossman, and C. Morimoto. 1991 Cyclic regulation of CD45 isoform expression in a long term human $\mathrm{CD}^{+}{ }^{+} \mathrm{CD}_{45 \mathrm{RA}}{ }^{+} \mathrm{T}$ cell line. J. Immunol. 146:1175-1183.

14. Gray, D. 1993. Immunological memory. Annu. Rev. Immunol. 1993:4977.

15. Sanders, M. E., M. W. Makgoba, S. O. Sharrow, D. Stephany, T. Springer, H. A. Young, and S. Shaw. 1988. Human memory T lymphocytes express increased levels of three cell adhesion molecules (LFA-3, CD2, and LFA-1) and three other molecules (UCHL1, CD229, and Pgp-1) and have enhanced IFN- $\gamma$ production. J. Immunol. 140:1401-1407.
16. Picker, L. J., J. R. Treer, D. B. Ferguson, P. A. Collins, D. Buck, and L. W. Terstappen. 1993. Control of lymphocyte recirculation in man. I. Differential regulation of the peripheral lymph node homing receptor $\mathrm{L}$-selectin on $\mathrm{T}$ cells during the virgin to memory cell transition. J. Immunol. 150:1105-1121.

17. Roederer, M., J. G. Dubs, M. T. Anderson, P. A. Raju, L. A. Herzenberg, and L. A. Herzenberg. 1995. CD8 naive T cell counts decrease progressively in HIV-infected adults. J. Clin. Invest. 95:2061-2066.

18. Roederer, M., F. J. T. Staal, M. T. Anderson, R. Rabin, P. A. Raju, L. A. Herzenberg, and L. A. Herzenberg. 1993. Disregulation of leukocyte glutathione in AIDS. In Clinical Flow Cytometry. A. L. Landay, K. A. Ault, K. D. Bauer, and P. S. Rabinovitch, editors. New York Academy of Sciences, New York. 113125.

19. Moore, W. A., and R. A. Kautz. 1986. Data analysis in flow cytometry. In Handbook of Experimental Immunology. D. M. Weir, L. A. Herzenberg, and L. A. Herzenberg, editors. Blackwell Scientific Publications, Edinburgh. 30.130.11

20. Okumura, M., Y. Fuji, K. Inada, K. Nakahara, and H. Matsuda. 1993. Both CD45RA ${ }^{+}$and $\mathrm{CD}^{2} 5 \mathrm{RA}^{-}$subpopulations of $\mathrm{CD}^{+} \mathrm{T}$ cells contain cells with high levels of lymphocyte function-associated antigen-1 expression, a phenotype of primed T cells. J. Immunol. 150:429-437.

21. Byrne, J. A., J. L. Butler, and M. D. Cooper. 1988. Differential activation requirements for virgin and memory $T$ cells. J. Immunol. 141:3249-3257.

22. Reddy, M. M., and M. H. Grieco. 1991. Quantitative changes in T helper inducer $\left(\mathrm{CD}^{+} \mathrm{CD}^{+} \mathrm{RA}^{-}\right)$, $\mathrm{T}$ suppressor inducer $\left(\mathrm{CD}^{+} \mathrm{CD}^{+} 5 \mathrm{RA}^{+}\right), \mathrm{T}$ suppres-

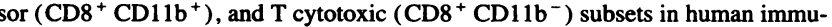
nodeficiency virus infection. J. Clin. Lab. Anal. 5:96-100.

23. Prince, H. E., and E. R. Jensen. 1991. Three-color cytofluorometric analysis of CD8 cell subsets in HIV-1 infection. J. Acquired Immune Defic. Syndr. 4:1227-1232.

24. Froebel, K. S., K. V. Doherty, J. A. Whitelaw, R. A. Hague, J. Y. Mok, and A. G. Bird. 1991. Increased expression of the CD45RO (memory) antigen on T cells in HIV-infected children. AIDS (Phila.). 5:97-99.

25. Church, J. A., G. Costin, and J. Brooks. 1989. Immune functions in children treated with biosynthetic growth hormone. J. Pediatr. 115:420-423.

26. Okumura, M., Y. Fujii, Y. Takeuchi, K. Inada, K. Nakahara, and H. Matsuda. 1993. Age-related accumulation of LFA-1 ${ }^{\text {high }}$ cells in a $\mathrm{CD}^{+}{ }^{+}$CD45RA ${ }^{\text {high }} \mathrm{T}$ cell population. Eur. J. Immunol. 23:1057-1063.

27. Bonyhadi, M. L., L. Rabin, S. Salimi, D. Brown, J. Kosek, J. McCune, and H. Kaneshima. 1993. HIV induces thymus depletion in vivo. Nature (Lond.). 363:728-732.

28. Smerdon, R. A., M. Peakman, M. J. Hussain, L. Alviggin, P. J. Watkins, R. D. Leslie, and D. Vergani. 1993. Increase in simultaneous coexpression of naive and memory lymphocyte markers at diagnosis of IDDM. Diabetes. 42:127133.

29. Semba, R. D., Muhilal, B. J. Ward, D. E. Griffin, A. L. Scott, G. Natadisastra, K. J. West, and A. Sommer. 1993. Abnormal T-cell subset proportions in vitamin-A-deficient children. Lancet. 341:5-8.

30. Cook, R. T., T. J. Waldschmidt, Z. K. Ballas, B. L. Cook, B. M. Booth, B. C. Steward, and M. J. Garvey. 1994. Fine T-cell subsets in alcoholics as determined by the expression of L-selectin, leukocyte common antigen, and $\beta$ integrin. Alcohol. Clin. Exp. Res. 18:71-80. 